\section{JURNAL EKONOMI EFEKTIF}

ISSN : $2622-8882$, E-ISSN : 2622-9935

Jurnal Ekonomi Efektif, Vol. 3, No. 1, Oktober 2020 @ Prodi Manajemen Fakultas Ekonomi Universitas Pamulang

\title{
PENGARUH STRATEGI PROMOSI TERHADAP MINAT BELI KONSUMEN PADA PT. TIGA SERANGKAI PUSTAKA MANDIRI
}

\author{
Ivantan $^{1 *}$, Neneng Khoiriah ${ }^{2}$, Sari Karmiyati ${ }^{3}$ \\ Universitas Pamulang \\ dosen02504@unpam.ac.id*
}

\begin{abstract}
ABSTRAK
Penelitian ini bertujuan untuk mengetahui pengaruh strategi promosi terhadap minat beli konsumen Pada PT. Tiga Serangkai Pustaka Mandiri. Metode yang digunakan adalah explanatory research dengan sampel sebanyak 96 responden. Teknik analisis menggunakan analisis statistik dengan pengujian regresi, korelasi, determinasi dan uji hipotesis. Hasil penelitian ini variabel strategi promosi diperoleh nilai rata-rata skor sebesar 3,400 dengan kriteria baik. Variabel minat beli diperoleh nilai rata-rata skor sebesar 3,831 dengan kriteria baik. Strategi promosi berpengaruh positif dan signifikan terhadap minat beli dengan nilai persamaan regresi $Y=9,955+0,834 X$, dan nilai koefisien korelasi 0,763 atau memiliki tingkat hubungan yang kuat dengan nilai determinasi $58,2 \%$. Uji hipotesis diperoleh signifikansi 0,000 $<0,05$.
\end{abstract}

Kata Kunci: Strategi Promosi, Minat Beli.

\begin{abstract}
This study aims to determine the effect of promotional strategies on consumer buying interest at PT. Tiga Serangkai Pustaka Mandiri. The method used is explanatory research with a sample of 96 respondents. The analysis technique uses statistical analysis with regression testing, correlation, determination and hypothesis testing. The results of this study, the promotional strategy variable, obtained an average score of 3,400 with good criteria. Purchase interest variable obtained an average score of 3,831 with good criteria. Promotion strategy has a positive and significant effect on purchase intention with the regression equation $Y=9.955+0.834 X$, and the correlation coefficient value of 0.763 or having a strong level of relationship with a determination value of $58.2 \%$. Hypothesis testing obtained a significance of $0.000<0.05$.
\end{abstract}

Keywords: Promotion Strategy, Buying Interest. 


\section{PENDAHULUAN}

\section{A. Latar Belakang Masalah}

Pemasaran merupakan salah satu dari kegiatan-kegiatan pokok yang dilakukan oleh para pengusaha dalam usahanya untuk mempertahankan kelangsungan hidupnya, untuk berkembang dan mendapat laba. Berhasil tidaknya dalam pencapaian tujuan bisnis tergantung pada keahlian mereka di bidang pemasaran, produksi, keuangan, maupun bidang lain. Selain itu juga tergantung pada kemampuan mereka untuk mengombinasikan fungsi-fungsi tersebut agar organisasi dapat berjalan lancer. Definisi pemasaran adalah suatu sistem keseluruhan dari kegiatan-Kegiatan bisnis yang ditujukan untuk merencanakan, menentukan harga, mempromosikan dan mendistribusikan barang dan jasa yang memuaskan kebutuhan baik kepada pembeli yang ada maupun pembeli potensial (Stanton dalam Swasta, 1996:5). Definisi lain tentang pemasaran adalah kegiatan manusia yang diarahkan pada usaha untuk memuaskan keinginan dan kebutuhan melalui proses pertukaran (Kotler dalam Swastha,1996:5).

Pemasaran dapat ditinjau sebagai suatu sistem dari kegiatan-kegiatan yang saling berhubungan, ditujukan untuk merencanakan, menentukan harga, Mempromosian dan mendistribusikan barang dan jasa kepada kelompok Pembeli. Kebijakan keputusan dalam pemasaran hampir selalu berkaitan dengan Variabel variabel marketing mix. variabel-variabel marketing mix tersebut adalah produk, harga, distribusi dan promosi. Oleh karena itu marketing mix sangat penting dan dapat digunakan sebagai alat pemasaran yang praktis.

Salah satu variable marketing mix adalah promosi. Promosi dipandangSebagai arus informasi persuasi satu arah yang dibuat untuk mengarahkan seseorang atau organisasi kepada tindakan yang menciptakan pertukaranan dan Pemasaran (Swastha, 1996:237). Untuk mendapatkan penjualan yang menguntungkan, promosi dan Kegiatan pemasaran harus di rencanakan dan dilaksanakan dengan baik. maka perusahaan dapat melakukan kegiatan promosi dengan strategi promotional mix dengan melakukan periklanan, personal selling, promosi penjualan dan publisitas. Dengan adanya promosi di harapkan dapat memberikan informasi selengkapnya kepada calon konsumen tentang barang yang ditawarkan, membujuk calon konsumen agar mau membeli barang/jasa yang ditawarkan dan mengingatkan pada konsumen tentang produk yang ada, harga yang berlaku dan lokasi tempat untuk mendapatkan produk tersebut.

Dengan demikian, harus diakui bahwa dalam melakukan kegiatan promosi, hal yang lebih penting adalah bagaimana mengkombinasikan variablel-variabel yang ada dalam promosi tersebut secara efektif, sehingga mampu meningkatkan penjualan secara maksimal. Dalam era modern ini media cetak semakin berkembang di masyarakat seperti surat kabar dan kebutuhan buku untuk menunjang pendidikan.

Perkembangan media cetak tersebut mendorong usaha penerbitan dan percetakan juga makin berkembang dan mengakibatkan persaingan bisnis ini menjadi ketat. perlu adanya usaha dari perusahaan dalam menghadapi persaingan itu. Kegiatan promosi akan sangat membantu memasarkan produk untuk meningkatkan penjualan perusahan.

Pentingnya kegiatan promosi juga di rasakan oleh PT. Tiga Serangkai Pustaka Mandiri sebuah perusahaan distribusi General Book yang menyediakan berbagai jenis kategori buku, mulai dengan buku anak-anak, novel remaja, dewasa, Al-Quran dan buku sekolah. Perusahaan ini bertempat tinggal di Jl. M. Kafi 1, Kelurahan Jagakarsa, Kecamatan Jagakarsa, Jakarta selatan. Perusahaan ini bekerjasama dengan toko-toko buku di Jakarta seperti Gramedia, Gunung Agung, Togamas bookstore, dan alternatif market lainya. dalam menghadapi persaingan yang semakin ketat dengan perusaan yang Sejenis di Jakarta dan sekitarnya. Hal ini mengharuskan PT. Tiga Serangkai pustaka 
mandiri untuk meningkatkan usahanya dalam rangka menghadapi persaingan dengan cara meningkatkan volume penjualan.

Salah satu usaha yang di tempuh oleh PT. Tiga Serangkai pustaka Mandiri adalah dengan cara melakukan peningkatan kegiatan promosi. Promosi dilakukan berbagai dengan cara seperti mengadakan kegiatan program pameran buku dengan diskon yang menarik ke berbagai toko yang sebelumnya sudah menjalin kerjasama dan perjanjian, metode kedua melakukan program luckydip yaitu promosi belanja dengan minimal harga akan mendapatkan hadiah langsung berupa souvenir seperti boneka, meja belajar, sajadah, tasbih dan banyak lainya, metode ke ketiga melakukan kunjungan ke berbagai instansi baik pemerintah maupun swasta dengan mencari order dan pembagian brosur mengenai jasa penerbitan dan percetakan kusus untuk buku sekolah, biasanya dilakukan pada saat-saat tahun ajaran baru. Kegiatan promosi di atas dilakukan tiap tahun dengan porsi yang berbeda, disesuaikan dengan kebutuhan atau target penjualan yang hendak dicapai.

Berdasarkan latar belakang tersebut penulis bermaksud melakukan penelitian ini dengan judul: Pengaruh Strategi Promosi Terhadap Minat Beli Konsumen Pada PT. Tiga Serangkai Pustaka Mandiri”

\section{B. Rumusan Masalah}

1. Bagaimana strategi promosi Pada PT. Tiga Serangkai Pustaka Mandiri ?.

2. Bagaimana minat beli konsumen Pada PT. Tiga Serangkai Pustaka Mandiri ?.

3. Adakah pengaruh antara strategi promosi terhadap minat beli konsumen Pada PT. Tiga Serangkai Pustaka Mandiri?.

\section{Tujuan Penelitian}

1. Untuk mengetahui kondisi strategi promosi Pada PT. Tiga Serangkai Pustaka Mandiri.

2. Untuk mengetahui kondisi minat beli konsumen Pada PT. Tiga Serangkai Pustaka Mandiri.

3. Untuk mengetahui pengaruh antara strategi promosi terhadap minat beli konsumen Pada PT. Tiga Serangkai Pustaka Mandiri.

\section{METODE PENELITIAN}

\section{Populasi}

Populasi dalam penelitian ini berjumlah 96 responden PT. Tiga Serangkai Pustaka Mandiri

2. Sampel

Teknik pengambilan sampling dalam penelitian ini adalah sampel jenuh, dimana semua anggota populasi dijadikan sebagai sampel. Dengan demikian sampel dalam penelitian ini berjumlah 96 responden.

\section{Jenis Penelitian}

Jenis penelitian yang dipakai adalah asosiatif, dimana tujuannya adalah untuk mengetahui atau mencari keterhubungan antara variabel independen terhadap variabel dependennya

\section{Metode Analisis Data}

Dalam menganalisis data digunakan uji validitas, uji reliabilitas, analisis regresi linier sederhana, koefisien korelasi, koefisien determinasi dan uji hipotesis. 


\section{HASIL PENELITIAN DAN PEMBAHASAN}

\section{Analisis Deskriptif}

Pada pengujian ini digunakan untuk mengetahui skor minimum dan maksimum skor tertinggi, ratting score dan standar deviasi dari masing-masing variabel. Adapun hasilnya sebagai berikut:

Tabel 1. Hasil Analisis Descriptive Statistics

\section{Descriptive Statistics}

\begin{tabular}{lr|r|r|r|r} 
& N & Minimum & Maximum & Mean & \multicolumn{1}{c}{ Std. Deviation } \\
\hline Strategi Promosi (X) & 96 & 27 & 44 & 34.00 & 3.885 \\
\hline Minat Beli (Y) & 96 & 29 & 49 & 38.31 & 4.248 \\
\hline Valid N (listwise) & 96 & & & & \\
\hline
\end{tabular}

Strategi promosi diperoleh varians minimum sebesar 27 dan varians maximum 44 dengan ratting score sebesar 3,400 dengan standar deviasi 3,885. Skor ini termasuk pada rentang sakala 3,40-4,19 dengan kriteria baik atau setuju.

Minat beli diperoleh varians minimum sebesar 29 dan varians maximum 49 dengan ratting score sebesar 3,831 dengan standar deviasi 4,248. Skor ini termasuk pada rentang sakala 3,40-4,19 dengan kriteria baik atau setuju.

\section{Analisis Verifikatif.}

Pada analisis ini dimaksudkan untuk mengetahui pengaruh variabel independen terhadap variabel dependen. Adapun hasil pengujian sebagai berikut:

\section{a. Analisis Regresi Linier Sederhana}

Uji regresi ini dimaksudkan untuk mengetahui perubahan variabel dependen jika variabel independen mengalami perubahan. Adapun hasil pengujiannya sebagai berikut:

Tabel 2. Hasil Pengujian Regresi Linier Sederhana

\begin{tabular}{|c|c|c|c|c|c|}
\hline \multirow[b]{3}{*}{ Model } & \multicolumn{2}{|c|}{ Coefficients $^{a}$} & \multirow[b]{2}{*}{$\begin{array}{l}\text { Standardized } \\
\text { Coefficients }\end{array}$} & \multirow[b]{3}{*}{$t$} & \multirow[b]{3}{*}{ Sig. } \\
\hline & $\begin{array}{r}\text { Unsta } \\
\text { Cos }\end{array}$ & $\begin{array}{l}\text { dardized } \\
\text { ficients }\end{array}$ & & & \\
\hline & B & Std. Error & Beta & & \\
\hline 1 (Constant) & 9.955 & 2.496 & & 3.989 & .000 \\
\hline Strategi Promosi $(\mathrm{X})$ & .834 & .073 & .763 & 11.435 & .000 \\
\hline
\end{tabular}

Berdasarkan hasil pengujian pada tabel di atas, diperoleh persamaan regresi $\mathrm{Y}$ $=9,955+0,834 \mathrm{X}$. Dari persamaan tersebut dijelaskan sebagai berikut:

1) Konstanta sebesar 9,955 diartikan jika strategi promosi tidak ada, maka telah terdapat nilai minat beli sebesar 9,955 point.

2) Koefisien regresi strategi promosi sebesar 0,834 , angka ini positif artinya setiap ada peningkatan strategi promosi sebesar 0,834 point maka minat beli juga akan mengalami peningkatan sebesar 0,834 point.

\section{b. Analisis Koefisien Korelasi}

Analisis koefisien korelasi dimaksudkan untuk mengetahui tingkt kekuatan hubungan dari variabel independen terhadap variabel dependen. Adapun hasil pengujian sebagai berikut: 
Tabel 3. Hasil Pengujian Koefisien Korelasi Strategi promosi Terhadap Minat beli. Correlations $^{b}$

\begin{tabular}{llr|r} 
& & \multicolumn{1}{c}{$\begin{array}{c}\text { Strategi } \\
\text { promosi }(\mathrm{X} 1)\end{array}$} & \multicolumn{1}{c}{ Minat beli $(\mathrm{Y})$} \\
\hline Strategi Promosi $(\mathrm{X})$ & Pearson Correlation & 1 & $.763^{* *}$ \\
\cline { 2 - 4 } & Sig. (2-tailed) & & .000 \\
\hline Minat Beli $(\mathrm{Y})$ & Pearson Correlation & $.763^{* *}$ & 1 \\
\cline { 2 - 4 } & Sig. (2-tailed) & .000 & \\
\hline
\end{tabular}

Berdasarkan hasil pengujian diperoleh nilai korelasi sebesar 0,763 artinya strategi promosi memiliki hubungan yang kuat terhadap minat beli.

\section{c. Analisis Koefisien Determinasi}

Analisis koefisien determinasi dimaksudkan untuk mengetahui besarnya persentase pengaruh dari variabel independen terhadap variabel dependen. Adapun hasil pengujian sebagai berikut:

Tabel 4. Hasil Pengujian Koefisien Determinasi Strategi promosi Terhadap Minat beli. Model Summary

\begin{tabular}{lr|r|rr|r} 
& & & \multicolumn{2}{c}{ Adjusted R } & \multicolumn{2}{c}{$\begin{array}{c}\text { Std. Error of the } \\
\text { Estimate }\end{array}$} \\
\hline 1 & $\mathrm{R}$ & R Square & Square & 2.762 \\
\hline
\end{tabular}

Berdasarkan hasil pengujian diperoleh nilai determinasi sebesar 0,582 artinya strategi promosi memiliki kontribusi pengaruh sebesar 58,2\% terhadap minat beli, sedangkan sisanya sebesar $41,8 \%$ dipengaruhi faktor lain.

\section{d. Uji Hipotesis}

Pengujian hipotesis dengan uji t digunakan untuk mengetahui hipotesis mana yang diterima.

Rumusan hipotesis: Terdapat pengaruh yang signifikan antara strategi promosi terhadap minat beli.

Tabel 5. Hasil Uji Hipotesis Strategi promosi Terhadap Minat beli. Coefficients $^{\mathrm{a}}$ Unstandardized

\begin{tabular}{|c|c|c|c|c|c|}
\hline \multirow[b]{2}{*}{ Model } & \multicolumn{2}{|c|}{$\begin{array}{l}\text { Unstandardized } \\
\text { Coefficients }\end{array}$} & \multirow{2}{*}{$\begin{array}{l}\text { Standardized } \\
\text { Coefficients } \\
\text { Beta }\end{array}$} & \multirow[b]{2}{*}{ 领 } & \multirow[b]{2}{*}{ Sig. } \\
\hline & B & Std. Error & & & \\
\hline 1 (Constant) & 9.955 & 2.496 & & 3.989 & .000 \\
\hline Strategi Promosi $(\mathrm{X})$ & .834 & .073 & .763 & 11.435 & .000 \\
\hline
\end{tabular}

Berdasarkan hasil pengujian pada tabel di atas, diperoleh nilai t hitung $>\mathrm{t}$ tabel atau $(11,435>1,984)$, dengan demikian hipotesis yang diajukan bahwa terdapat pengaruh yang signifikan atara strategi promosi terhadap minat beli diterima.

\section{PEMBAHASAN HASIL PENELITIAN}

\section{Kondisi Jawaban Responden Variabel Strategi Promosi}

Berdasarkan jawaban responden, variabel strategi promosi diperoleh ratting score sebesar 3,400 berada di rentang skala 3,40-4,19 dengan kriteria baik atau setuju.

\section{Kondisi Jawaban Responden Variabel Minat Beli}

Berdasarkan jawaban responden, variabel minat beli diperoleh ratting score sebesar 3,831 berada di rentang skala 3,40 - 4,19 dengan kriteria baik atau setuju.

\section{Pengaruh Strategi promosi Terhadap Minat Beli}

Strategi promosi berpengaruh signifikan terhadap minat beli dengan persamaan 
regresi $\mathrm{Y}=9,955+0,834 \mathrm{X}$, nilai korelasi sebesar 0,763 atau memiliki hubungan yang kuat dengan kontribusi pengaruh sebesar 58,2\%. Pengujian hipotesis diperoleh nilai t hitung $>\mathrm{t}$ tabel atau $(11,435>1,984)$. Dengan demikian hipotesis yang diajukan bahwa terdapat berpengaruh signifikan antara strategi promosi terhadap minat beli diterima.

\section{V.PENUTUP}

\section{Kesimpulan}

a. Variabel strategi promosi diperoleh ratting score sebesar 3,400 berada di rentang skala 3,40 - 4,19 dengan kriteria baik atau setuju.

b. Variabel minat beli diperoleh ratting score sebesar 3,831 berada di rentang skala 3,40 - 4,19 dengan kriteria baik atau setuju.

c. Strategi promosi berpengaruh signifikan terhadap minat beli dengan persamaan regresi $\mathrm{Y}=9,955+0,834 \mathrm{X}$, nilai korelasi sebesar 0,763 atau kuat dan kontribusi pengaruh sebesar 58,2\% sedangkan sisanya sebesar $41,8 \%$ dipengaruhi faktor lain. Uji hipotesis diperoleh nilai $t$ hitung $>\mathrm{t}$ tabel atau $(11,435>1,984)$.

\section{Saran}

a. Perusahaan harus mampu mengombinasikan strategi promosi yang tepat dalam memanfaat media elektronik guna meningkatkan minat beli konsumen.

b. Perusahaan harus selalu mengupdate kebutuhan pasar utamanya buku-buku yang banyak digunakan dalam dunia pendidikan baik tingkat sekolah anak-anak sampai perguruan tinggi.

\section{DAFTAR PUSTAKA}

Algifari. (2015). “Analisis Regresi untuk Bisnis dan Ekonomi”. Yogyakarta: BPFE.

Arikunto, Suharsimi (2014). "Prosedur Penelitian Suatu Pendekatan Praktek". Jakarta: Rineka Cipta.

Bashu Swastha dan T. Handoko (2015) Manajemen Pemasaran Moderen, Yogyakarta: BPFE.

Basu Swastha Dharmmesta. (2014). Manajemen Pemasaran. BPFE: Yogyakarta. Buchari Alma. 2014. Manajemen pemasaran dan Pemasaran Jasa. Edisi Revisi.

Bilson Simamora (2016) Panduan Riset Prilaku Konsumen, Jakarta: PT. Gramedia Pustaka. Fandy Tjiptono (2017), Serivce Quality and Satisfiation. Jakarta: Edisi tiga. Andi.

Freddy Rangkuti (2016) Strategi Promosi Yang Kreatif, Edisi Pertama, Cetakan Pertama Jakarta: Gramedia Pustaka Utama.

Imam Ghozali (2017). “Aplikasi Analisis Multivariate Dengan Program SPSS”. Edisi Kelima. Semarang: Badan Penerbit Undip.

Istijanto (2014) “Riset Sumber Daya Manusia”. Jakarta: PT. Gramedia Pustaka

Kharis, Ismu Fadli (2011). "Studi Mengenai Impulse Buying dalam Penjualan Online”. Semarang : Skripsi Universitas Diponegoro

Kotler dan Amstrong (2017), Prinsip-prinsip Pemasaran. Edisi Kedua Belas”. Jilid Satu. Jakarta: Erlangga.

Lupiyoadi (2016) Manajemen Pemasaran Jasa, Edisi 4, Jakarta: Salemba Empat.

Philip Kotler (2017) Manajemen Pemasaran, Edisi Keempat Belas, Jakarta: PT. Indeks.

Phipil Kotler dan Kevin Keller (2017) Manajemen Pemasaran, Edisi Kedua Belas, Jilid Satu, Jakarta: Erlangga.

Rao, Purba, (2012). “Measuring Consumer Perceptions Through Factor Analysis”, The Asian.

Santoso, Singgih (2015). "Menguasai Statistik Multivariat”. Jakarta: PT Elex Media 
Komputindo.

Sudjana (2014) “Metode Statistika”, Bandung: Tarsido.

Sugiyono (2017), "Metode Penelitian Administrasi : dilengkapi dengan Metode $R \&$ D". Bandung: Alfabeta.

Suhartanto (2014). “Metode Riset Pemasaran”. Bandung: Alfabeta

Sunarsi, D. (2017). Pengaruh Rekrutmen, Seleksi dan Pelatihan Terhadap Produktivitas Kerja Karyawan PT Mercolade Tangerang.

Sunarsi, D. (2018). Pengembangan Sumber Daya Manusia Strategik \& Karakterisrik Sistem Pendukungnya : Sebuah Tinjauan. Jurnal Ilmiah MEA (Manajemen, Ekonomi, \& Akuntansi). Vol 2 No 3

Yuangga, K. D., \& Sunarsi, D. (2018). The Influence of Procrastination and Low Time Management on Student Self Efficacy (at MA Soebono Mantofani). PINISI Discretion Review, 2(1), 85-92. 